\title{
Effect of Qiwei Baizhu Powder on the Intestinal Flora of the Splenoasthenic Diarrhea Mice
}

\author{
X. SHI, NA LI, JING LI, QING YANG, M. KAN AND X. QU* \\ Jilin Ginseng Academy, Changchun University of Chinese Medicine, Changchun City-130117, Jilin Province, China
}

Shi et al.: Effect of qiwei baizhu powder in splenoasthenic diarrhea mice

\begin{abstract}
To explore the effect of Qiwei Baizhu Powder on the intestinal flora of splenoasthenic diarrhea mice and its mechanism. The splenoasthenic diarrhea mouse model established by different modeling methods (antibiotics and traditional Chinese medicine compound prescription) was used as the experimental group, and a blank control group was set up at the same time. Qiwei Baizhu Powder was used to treat the splenoasthenic diarrhea model mice. The splenoasthenic diarrhea mouse model established by taking Dachenqi Tang (Traditional Chinese medicine Group) had the most severe splenoasthenic diarrhea and poor mental state, while without significant effect on intestinal flora $(p>0.05)$. The splenoasthenic diarrhea mouse model constructed by gentamicin sulfate and cefradine (Antibiotic combination group) had the best effect. The results of the antimicrobial spectrum showed that the gentamicin sulfate and cefradine could form the maximum complementary effect and the effect was long-lasting. After the intragastric administration of Qiwei Baizhu Powder, the mice in the Traditional Chinese medicine Group were quickly cured and the syndrome of splenoasthenic diarrhea disappeared. The number of intestinal lactic acid bacteria and fungi in the antibiotic combination group was significantly higher than that in the normal group $(\mathbf{p}<\mathbf{0 . 0 1})$. In Qiwei Baizhu Powder, there are probiotics that promote the growth of lactic acid bacteria and fungi, which can cure the imbalance of intestinal flora.
\end{abstract}

Key words: Qiwei Baizhu Powder, Splenoasthenic diarrhea, Mouse model, Intestinal flora

In traditional Chinese medicine (TCM), the "spleen" is completely different from the spleen organs in western medicine. In TCM, the spleen is related to the stomach, which is responsible for the assimilation of food and liquid and transformation into nutrients available to the human body ${ }^{[1]}$. Therefore, dyssplenism in TCM is the general name of the digestive and circulatory syndrome of various related diseases ${ }^{[2-4]}$. Typical features of dyssplenism include loss of appetite and indigestion, fatigue and hemorrhagic diseases. Spleen deficiency syndrome (SDS) is a typical TCM syndrome characterized by loss of appetite, fullness and drowsiness after eating, fatigue, pale face and tongue, weight loss and sparse stools ${ }^{[5]}$. Spleen-yang deficiency syndrome (SYDS) is one of the commonest types of SDS. Patients with SYDS are usually diagnosed with abnormalities of the gastrointestinal system, such as splenoasthenic diarrhea, chronic gastroenteritis or hepatitis and Candida infection ${ }^{[6-9]}$. However, up to now, the biological mechanism of SYDS is not clear.

The human body can be called a "superorganisms" due to the human body is made up of cells, tissues, and

*Address for correspondence

E-mail: xiaobo@163.com organs. This "superorganisms" is not only composed of normal cells of the human body, but also includes a large number of symbiotic microorganisms on the body surface and intestines. Symbiotic microorganism plays a key role in maintaining human health in the intestinal tract. So as a superorganism, we have two sets of genomes, the host genome and the microbialencoded genome ${ }^{[10-13]}$. Intestinal flora participates in the utilization of intestinal polysaccharides, which is very important to the function of the human digestive system $^{[14-16]}$. As described in the theory of TCM, SYDS is a complex phenotype, which reflects the overall change of digestive system disorders ${ }^{[3,5,17]}$. Therefore, theoretically speaking, intestinal flora disorder may promote the development of SYDS ${ }^{[18]}$. However, there is no evidence of this hypothesis in clinical practice.

This is an open access article distributed under the terms of the Creative Commons Attribution-NonCommercial-ShareAlike 3.0 License, which allows others to remix, tweak, and build upon the work non-commercially, as long as the author is credited and the new creations are licensed under the identical terms

Accepted 14 September 2020 Revised 01 August 2020 Received 09 June 2020 Indian J Pharm Sci 2020;82(5):828-835 
In medical research, in order to clarify the pathogenesis of the disease or the efficacy of drugs, it is necessary to establish animal disease models. The establishment of splenoasthenic diarrhea model is an important means to study the pathogenesis of splenoasthenic diarrhea. Different types of splenoasthenic diarrhea need to establish the corresponding model, and the establishment of the model is the basis of medical research, the quality of the model is directly related to the success or failure of the research. Many factors can cause splenoasthenic diarrhea, the splenoasthenic diarrhea treated with TCM compound prescription has been widely recognized at home and abroad. A large number of studies have confirmed that the effect of TCM compound prescription in the treatment of splenoasthenic diarrhea is better than that of western medicine $^{[2]}$. The original prescription of Qiwei Baizhu powder is contained in the second volume of XiaoEr YaoZheng ZhiJue, er qian wu fen ginseng, wu qian poria alba, wu qian baizhu (Fried), wu qian wrinkled giant hyssop, er qian radices saussureae, yi qian liquorice, wu qian the root of kudzu vine (Thirsty to yi liang). It has the function of invigorating spleen and generating body fluid, promoting qi circulation to relieve flatulence, and strengthening the body resistance to eliminate pathogenic factors. Clinical practice shows that, Qiwei Baizhu powder has a good therapeutic effect on many intestinal diseases such as antibiotic-induced splenoasthenic diarrhea, and infantile persistent splenoasthenic diarrhea. Modern pharmacological and pharmacodynamic studies have shown that, Qiwei Baizhu powder can restore the imbalance of intestinal microorganisms to normal, and make intestinal microorganisms reach a new balance ${ }^{[4]}$. Therefore, in this study, different modeling methods of splenoasthenic diarrhea were studied by appearance symptoms and intestinal microbial culture, and the recovery effect of ultra-micro Qiwei Baizhu powder on splenoasthenic diarrhea model was studied in order to provide experimental basis for the establishment of mouse splenoasthenic diarrhea model.

\section{MATERIALS AND METHODS}

\section{Animals and feed}

Specific pathogen-free (SPF) mice were purchased from the Shanghai Lab Animal Research Center of Chinese Academy of Sciences. The feed used in this experiment was provided by the Animal Experimental Center of Jiangxi University of Traditional Chinese Medicine.

\section{Drugs and reagents}

The medicinal materials in the Dachenqi Tang compound are identified and provided by the department of TCM in our hospital (Rheum officinale, glauber salt, Mangnolia officinalis, Fructus aurantii immaturus, $<$ Pharmacopoeia of People's Republic of China $>$, 2010 edition). Common drugs used in this experiment include gentamicin sulfate injection, cefradine capsule, lincomycin hydrochloride injection, erythromycin lactobionate, ceftriaxone sodium injection, ampicillin sodium injection and ultra-micro Qiwei Baizhu powder (ginseng, licorice, the root of kudzu vine, Saussurea lappa, fried baizhu, wrinkled giant hyssop, poria alba.

\section{Culture media}

The bacterial medium was Lysogeny broth (LB) medium $^{[5]}$, the fungal medium was martin rose bengal streptomycin agar medium ${ }^{[5]}$, the Escherichia coli medium was eosin methylene blue agar medium (EMB) ${ }^{[5]}$, and the lactic acid bacteria medium was De Man, Rogosa and Sharpe (MRS) agar medium ${ }^{[6]}$.

\section{Experimental animal grouping}

A total of 60 SPF mice (30 male and 30 female, weighing $18 \pm 2 \mathrm{~g})$ was randomly divided into 5 groups after $4 \mathrm{~d}$ of adaptive feeding, ampicillin and lincomycin hydrochloride combination group (group A), ceftriaxone and erythromycin combination group (group B), gentamicin and cefradine combination group (group C), Dachenqi Tang group (group D) and control group (group E). After the success of the model, half of the mice in each group were dissected and analyzed for intestinal microorganisms, and the other half were given intragastric administration of ultra-micro Qiwei Baizhu powder, the control group to continue intragastric administration of normal saline.

\section{Modeling method}

Group A, a combination of lincomycin hydrochloride and ampicillin ${ }^{[7]}$. According to the body weight of the tested mice, each mouse was given a dosage of $30 \mathrm{mg}$ and $60 \mathrm{mg} / \mathrm{d}$, respectively. Then, $0.3 \mathrm{ml}$ of the mixed solution was given to the mice by intragastric administration twice a day, resulting in intestinal flora disorder. Group B, a combination of ceftriaxone and erythromycin ${ }^{[8-9]}$. According to the body weight of the tested mice, each mouse was given $30 \mathrm{mg} / \mathrm{d}$. Then, $0.3 \mathrm{ml}$ of the mixed solution was given to the mice by intragastric administration twice a day, resulting in intestinal flora disorder. Group C, a combination of gentamicin and cefradine ${ }^{[7]}$. According to the body weight of the tested mice, the daily doses of each mouse were $40 \mathrm{mg}$ and $30 \mathrm{mg}$, respectively. Then, $0.3 \mathrm{ml}$ of 
the mixed solution was given to the mice by intragastric administration twice a day, resulting in intestinal flora disorder. Group D, the model was made by diarrhea of bitter and cold method, and the decoction was prepared by Dachenqi Tang compound ${ }^{[10]}$, which including 27 $\mathrm{g}$ Rheum officinale, $18 \mathrm{~g}$ Mangnolia officinalis, $18 \mathrm{~g}$ Fructus aurantii immaturus, and 27 g glauber salt. In the preparation of the decoction, magnolia officinalis and Fructus aurantii immaturus were decocted first, then Rheum officinale was added, and finally glauber salt was added. Then, $0.3 \mathrm{ml}$ of the mixed solution was given to the mice by intragastric administration twice a day. The model group was treated continuously for 7 d. The control group was given $0.3 \mathrm{ml} /$ mouse normal saline twice a day.

\section{Ultra-micro Specifications and Method of Administration}

Traditional medicinal materials are baked at low temperature $\left(60^{\circ}\right)$, the coarse powder is prepared by the grinder, and ultra-micro powder is prepared by micronizer $\left(0-15^{\circ}\right)$. That is, Qiwei Baizhu ultra-micro powder ( $>200$ mesh), which was identified by the Research Center of traditional Chinese Medicine, Ultramicro Engineering Technology of Hunan Academy of traditional Chinese Medicine, and it meets the specification of ultra-micro powder. Ultra-micro Qiwei Baizhu powder was prepared by adding boiling water, stirring, cooling and low-speed centrifugation to get the supernatant. The administration dose refers to the ultra-micro Qiwei Baizhu powder dose given by Deng Hongjie et al. ${ }^{[11]}$, ultra-micro Qiwei Baizhu powder 1/2 dose per group [0.08 g/(kg/d)]. A total of $0.3 \mathrm{ml}$ of the mixed solution was given to the mice by intragastric administration twice a day for $5 \mathrm{~d}$.

\section{Clinical observation of the experimental animals}

The body weight, fecal color, coat color, mental status and death of mice were recorded before, after and after the treatment with ultra-micro Qiwei Baizhu powder.

\section{Extraction of the intestinal contents from mice}

The executed mice were immediately placed on the super clean bench, and the intestinal contents of each group mice from jejunum to rectum were aseptically collected, and the intestinal contents of mice in the same group were collected and mixed by aseptic operation for later use.

\section{Determination of the number of intestinal microbes}

A certain amount of intestinal contents from each group was placed in a triangular bottle containing glass beads and aseptic water, and shake for $30 \mathrm{~min}$ at $120 \mathrm{rpm}$ to fully disperse the microorganisms to a single existence as much as possible. Then select the appropriate dilution and count by the mixed bacteria method. Bacteria and Escherichia coli were cultured at $37^{\circ}$ for $24 \mathrm{~h}$, fungi were cultured at $30^{\circ}$ for $96 \mathrm{~h}$, lactic acid bacteria were anaerobic cultured at $37^{\circ}$ for $48 \mathrm{~h}$, and each dilution was repeated 3 times. The average value was taken and the number of microorganisms per gram of intestinal content was calculated.

\section{Statistical analysis}

The measurement data of each group were expressed by mean \pm standard deviation $(\mathrm{x} \pm \mathrm{s})$, and the data were processed by Data Processing System (DPS) v7.05 software. The mean between the two groups was compared by the t-test. $\mathrm{p}<0.05$ means there were significant differences.

\section{RESULTS AND DISCUSSION}

The degree of thinning and wetness of mouse feces during modeling and treatment was observed, the results are shown in fig. 1. During the modeling period (7d), the water intake of the mice in the group $\mathrm{E}$ was normal, the action was active, the coat was smooth, and the feces of the mice were dry and dark brown. In the antibiotic combined group, compared with the normal group, the feces of mice turned yellow, moist, slightly larger, mice were active and the coat color was normal $4^{\text {th }} \mathrm{d}$ after treatment. On the $5^{\text {th }} \mathrm{d}$ of treatment, the moderate splenoasthenic diarrhea appeared in the group B, which was stronger than that in group A and group C. On the last $2 \mathrm{~d}$ of modeling, the mice were treated with double dose of antibiotics, most of the mice in group A and $\mathrm{C}$ appeared moderate splenoasthenic diarrhea. In group $\mathrm{B}$, compared with the $5^{\text {th }} \mathrm{d}$, there was no significant difference in the degree of splenoasthenic diarrhea after doubling dose. And a small part of mice in group C showed severe splenoasthenic diarrhea, splenoasthenic diarrhea degree as group $\mathrm{C}>$ group $\mathrm{A}>$ group $\mathrm{B}$. In group $\mathrm{D}$, moderate splenoasthenic diarrhea appeared on the $1^{\text {st }} \mathrm{d}$ of treatment, and the degree of splenoasthenic diarrhea was the most obvious $1 \mathrm{~h}$ after intragastric administration, and improved after $5 \mathrm{~h}$. On the $5^{\text {th }} \mathrm{d}$ of treatment, most of the mice in group D had severe splenoasthenic diarrhea, hair turning, listlessness and fear of cold, and the mice in the cage were curled up together. On the $7^{\text {th }} \mathrm{d}$ of treatment, two female mice died in group D. During the modeling period, there was no decrease in food intake in the model group compared with the control group. Dissecting the intestinal contents, the cecum volume of group A, group B, group 
$\mathrm{C}$ and group D was significantly larger than that of the control group, which was morbid, and the relevant pathological studies need to be further studied.

The body weight of mice is intuitive and easy to examine index, and it is closely related to many factors. The body weight of mice before treatment was analyzed, and the results were shown in fig. 2 and 3. As can be seen from fig. 2, the body weight of mice in both the model group and the control group increased significantly, and the rate of weight change was larger (fig. 3). Compared with the control group, the body weight of mice in group $B(p<0.05)$ and $C(p<0.05)$ increased obviously slowly, which indicated that the antibiotics in group B (ceftriaxone sodium, erythromycin lactose) and C (cefradine, gentamicin sulfate) could slow down the weight growth of mice (Table 1).

The traditional microbiological technique-dilution plate colony counting method was used to analyze the culturable microorganisms in the intestinal tract of mice. Table 2 shows that after the mice in the antibiotic combination group was treated with antibiotics, the modeling effect of group $\mathrm{C}$ was the best, and the number of bacteria, lactic acid bacteria $(\mathrm{p}<0.01)$ and Escherichia coli $(\mathrm{p}<0.05)$ decreased significantly. The result of the bacterial count was consistent with the observation of the apparent characteristics of mice in group $\mathrm{C}$, and the degree of splenoasthenic diarrhea in group $\mathrm{C}$ was the most serious in the group treated with antibiotics. Gentamicin is a broad-spectrum antibiotic, which has good antibacterial activity against Enterobacteriaceae such as Escherichia coli, Proteus, Enterobacter. Most Enterococci were resistant to this drug, while cefradine had good antibacterial activity against Gram-positive cocci ${ }^{[12]}$. The combination of gentamicin and cefradine could show a good splenoasthenic diarrhea model effect. The modeling effect of group $\mathrm{A}$ is inferior to that of group $\mathrm{C}$ and the number of bacteria $(\mathrm{p}<0.05)$ and lactic acid bacteria $(p<0.01)$ decreased significantly. According to the apparent characteristics of mice, the degree of splenoasthenic diarrhea in group A was lower

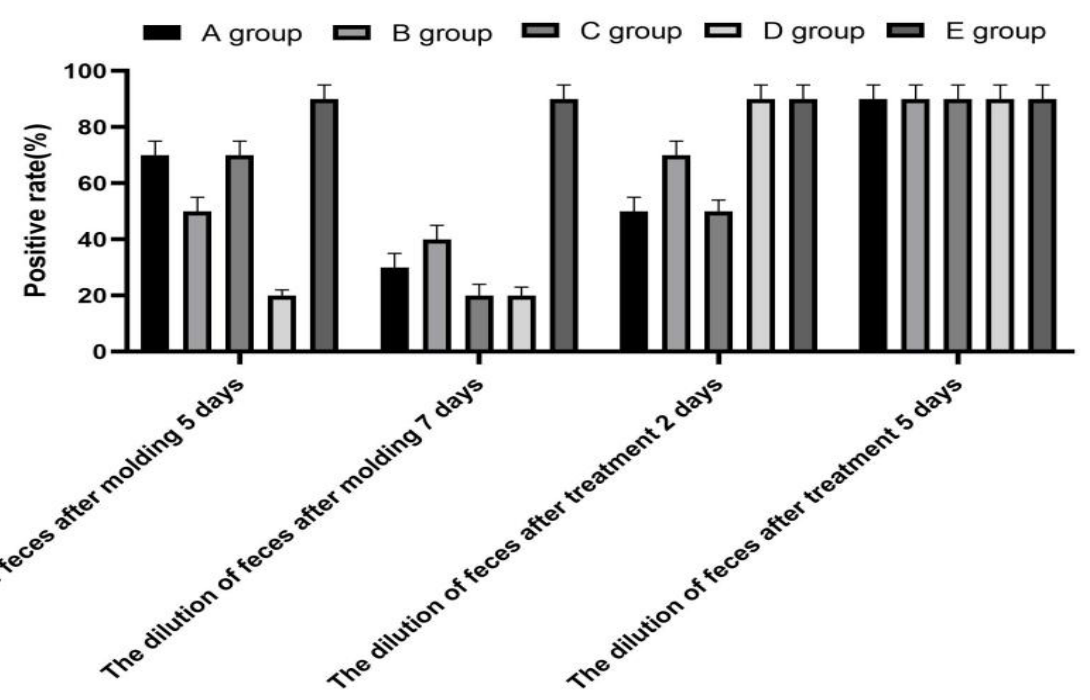

Fig. 1: Effects on the clinical features of mice

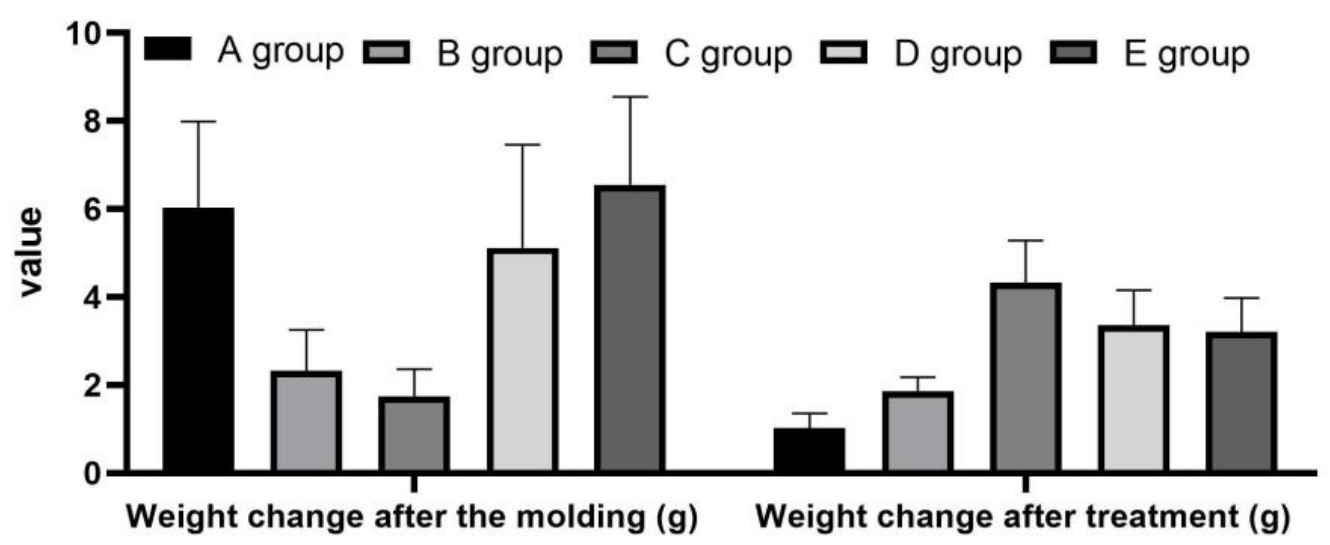

Fig. 2: Effects on mice weight 
than that of group $\mathrm{C}$ and stronger than that of group B. The combination of ampicillin sodium and lincomycin hydrochloride to produce the mouse splenoasthenic diarrhea is a classical method. Many scholars use this method to produce mouse splenoasthenic diarrhea, and show good results ${ }^{[8-12]}$. Ampicillin is broad-spectrum semisynthetic penicillin. It has strong antibacterial activity against Staphylococcus and Enterococcus, which does not produce penicillinase. Some Escherichia coli, Salmonella and Shigella bacteria are also sensitive to this product. Lincomycin has strong activity against Staphylococcus aureus and anaerobes, but not against Enterococcus and gram-negative bacteria or yeasts. The combination of ampicillin and lincomycin can also show a good splenoasthenic diarrhea model effect. The effect of modeling in group B was the worst, and the number of bacteria and Escherichia coli not decreased significantly $(\mathrm{p}>0.05)$.

According to the apparent characteristics of mice, the degree of splenoasthenic diarrhea in group B was lower than that in group A and group C. The reason is that erythromycin and ceftriaxone sodium are not well mixed with each other ${ }^{[12]}$, resulting in white turbidity and caking precipitation, which makes the combination of antibiotics invalid, and good splenoasthenic diarrhea effect can be shown when used alone ${ }^{[8-9]}$. The number of fungi increased significantly (group B and C, $\mathrm{p}<0.05$ ) in the antibiotic combination group. The combination of antibiotics had high activity against bacteria, resulting in a significant decrease in the number of intestinal bacteria, while the activity of antibiotics to fungi was lower, and fungi increased competitively in the intestine. In group D, Dachenqi Tang did not cause significant changes in intestinal flora (Table 2). However, from the apparent characteristics of mice, the degree of splenoasthenic diarrhea in group D was significantly stronger than that in the group of antibiotics combination, and the degree of splenoasthenic diarrhea in mice was especially serious within $1-5 \mathrm{~h}$ after the intragastric administration of Dachenqi Tang. Rheum officinale was the monarch drug in Dachenqi Tang prescription, which has the function of purgating heat and bowels, cleansing intestines and stomach, and can promote intestinal peristalsis ${ }^{[13]}$. Glauber salt was

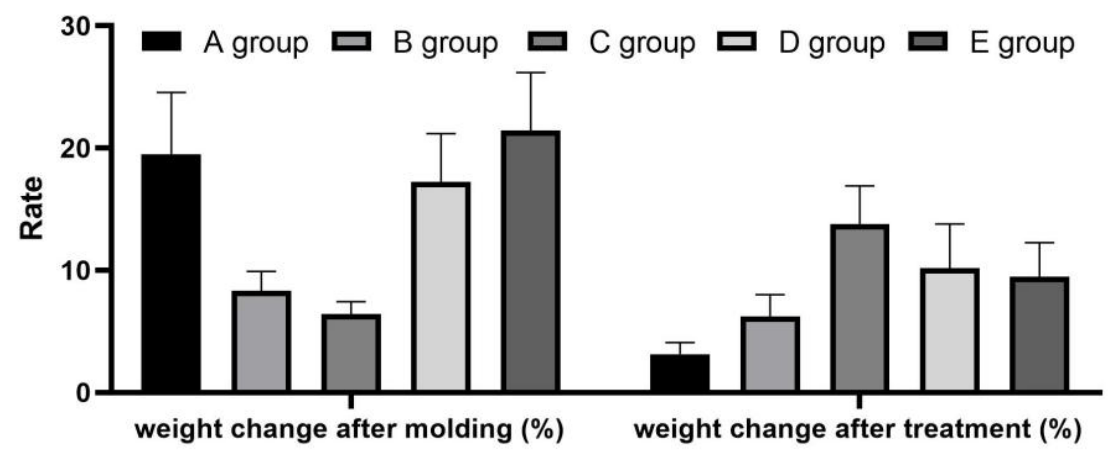

Fig. 3: Weight change rates after modeling and treatment in each group (\%)

TABLE 1: EFFECT ON MOUSE BODY WEIGHT ( $x \pm s, n=10)$

\begin{tabular}{lcccc}
\hline Group & $\begin{array}{c}\text { Weight change after the } \\
\text { molding }(\mathbf{g})\end{array}$ & $\begin{array}{c}\text { Rate of weight change } \\
\text { after the molding (\%) }\end{array}$ & $\begin{array}{c}\text { Weight change after } \\
\text { treatment }(\mathbf{g})\end{array}$ & $\begin{array}{c}\text { Rate of weight change } \\
\text { after treatment }(\%)\end{array}$ \\
\hline A Group & $6.04 \pm 1.95$ & $19.52 \pm 5.04$ & $1.02 \pm 0.33$ & $3.13 \pm 0.97$ \\
B Group & $2.33 \pm 0.92$ & $8.32 \pm 1.59$ & $1.86 \pm 0.32$ & $6.23 \pm 1.78$ \\
C Group & $1.74 \pm 0.62$ & $6.43 \pm 1.01$ & $4.33 \pm 0.96$ & $13.79 \pm 3.12$ \\
D Group & $5.12 \pm 2.34$ & $17.23 \pm 3.97$ & $3.36 \pm 0.79$ & $10.16 \pm 3.42$ \\
E Group & $6.55 \pm 2.00$ & $21.43 \pm 4.76$ & $3.2 \pm 0.78$ & $9.48 \pm 2.78$ \\
\hline
\end{tabular}

TABLE 2: THE EFFECT OF ANTIBIOTICS AND CHINESE MEDICINE ON INTESTINAL MICROBES IN MICE (x士s)

\begin{tabular}{lcccc}
\hline Group & $\begin{array}{c}\text { Bacteria } \\
\left(10^{7} \text { CFU/g) }\right.\end{array}$ & $\begin{array}{c}\text { Colibacillus } \\
\left(10^{7} \text { CFU /g) }\right.\end{array}$ & $\begin{array}{c}\text { Lactic acid bacteria } \\
\left(10^{7} \text { CFU/g) }\right.\end{array}$ & $\begin{array}{c}\text { Fungi } \\
\left(10^{6} \text { CFU/g) }\right.\end{array}$ \\
\hline Group A & $9.698 \pm 0.114$ & $2.143 \pm 0.186$ & $0.309 \pm 0.010$ & $0.426 \pm 0.029$ \\
Group B & $20.672 \pm 0.566$ & $9.964 \pm 0.287$ & $10.977 \pm 1.128$ & $14.648 \pm 0.134$ \\
Group C & $0.504 \pm 0.0363$ & $0.115 \pm 0.069$ & $0.380 \pm 0.030$ & $1.442 \pm 0.234$ \\
Group D & $77.347 \pm 9.041$ & $13.785 \pm 0.580$ & $17.278 \pm 0.652$ & $0.532 \pm 0.082$ \\
Group E & $37.163 \pm 2.177$ & $17.010 \pm 0.451$ & $10.250 \pm 0.442$ & $0.128 \pm 0.021$ \\
\hline
\end{tabular}


the ministerial drug in Dachenqi Tang prescription. The main component of glauber salt is sodium sulfate (lubricant), which can increase the volume of intestinal cavity and stimulate the intestinal wall ${ }^{[14]}$. It can help Rheum officinale to purge heat and defecate. Thus Dachenqi Tang can cause splenoasthenic diarrhea in mice in a short time. And taking Dachenqi Tang for a long time can damage the promordial Qi of the body and weaken the function of the spleen and stomach. In the experiment, it was observed that the mice showed similar syndrome of spleen deficiency, such as mental malaise, fear of cold, sparse and erect of hair, which could damage the immune function of the body after taking it for a long time ${ }^{[10]}$. The symptoms of mice treated with a large dose of Dachenqi Tang were consistent with the characteristics of splenoasthenic diarrhea in TCM, but it did not cause the imbalance of Intestinal flora (fig. 4).

Seven days after the establishment of the model, splenoasthenic diarrhea mice were treated with $1 / 2$ dose of ultra-micro Qiwei Baizhu powder, and then the apparent characteristics of the treated mice were analyzed. During the treatment period $(5 \mathrm{~d})$, the symptoms of splenoasthenic diarrhea in group B and D completely improved on the $2^{\text {nd }} \mathrm{d}$ of treatment, and the spirit of mice in group D returned to normal. The mice in group A improved on the $3^{\text {rd }} \mathrm{d}$ of treatment, and the splenoasthenic diarrhea in group $\mathrm{C}$ improved completely until the $5^{\text {th }} \mathrm{d}$ of treatment (fig. 1). During the modeling period, it was found that the cecal volume of group A, group $\mathrm{B}$, group $\mathrm{C}$ and group $\mathrm{D}$ was significantly larger than that of the control group. The change of body weight of mice after treatment was analyzed, and there was no significant difference in the change rate of body ( $p>0.05$, Table 3, fig. 1). Although the symptoms of splenoasthenic diarrhea have improved, the weight gain is slow. From the apparent characteristics of mice after dissection, it can be seen that the morbid cecum may be due to the destruction of the intestinal mucosa and intestinal wall structure after long-term treatment with antibiotics, which cannot be repaired immediately, and then affecting digestion and absorption.

In the antibiotic treatment group, the number of bacteria, Escherichia coli and lactic acid bacteria increased significantly after ultra-micro Qiwei Baizhu powder treatment, and the number of bacteria returned to the normal level $(\mathrm{p}>0.05)$. The analysis of specific microorganisms in the intestinal tract of mice showed that the number of Escherichia coli in group A increased $(p<0.05)$, the number of lactic acid bacteria in group $\mathrm{A}$, group $\mathrm{B}$ and group $\mathrm{C}$ increased significantly too $(p<0.05)$. In the antibiotic combination group, the number of fungi in the intestinal tract increased competitively due to the treatment of ultra-micro Qiwei Baizhu powder $(\mathrm{p}<0.01)$. It may be due to the existence of certain probiotics in the ultra-micro Qiwei Baizhu powder, which can promote the growth of Escherichia coli, lactic acid bacteria and fungi in the case of intestinal flora imbalance. From fig. 3, there was no significant change in the number of bacteria, Escherichia coli, lactic acid bacteria and fungi in group D compared with the control group $(p>0.05)$. It shows that Dachenqi Tang does not cause splenoasthenic diarrhea due to the imbalance of intestinal flora. However, in group D, splenoasthenic diarrhea improved completely on the $2^{\text {nd }}$ $\mathrm{d}$ after treatment, and the symptoms of spleen deficiency such as listlessness, chills, hair sparse and erection also disappeared, indicating that Qiwei Baizhu powder has a good effect on splenoasthenic diarrhea, which has also been confirmed in other studies ${ }^{[15]}$ (Table 4).

In recent years, due to the widespread use or abuse of antibiotics, intestinal flora disorders and even intestinal flora drug resistance has become increasingly serious ${ }^{[16]}$,

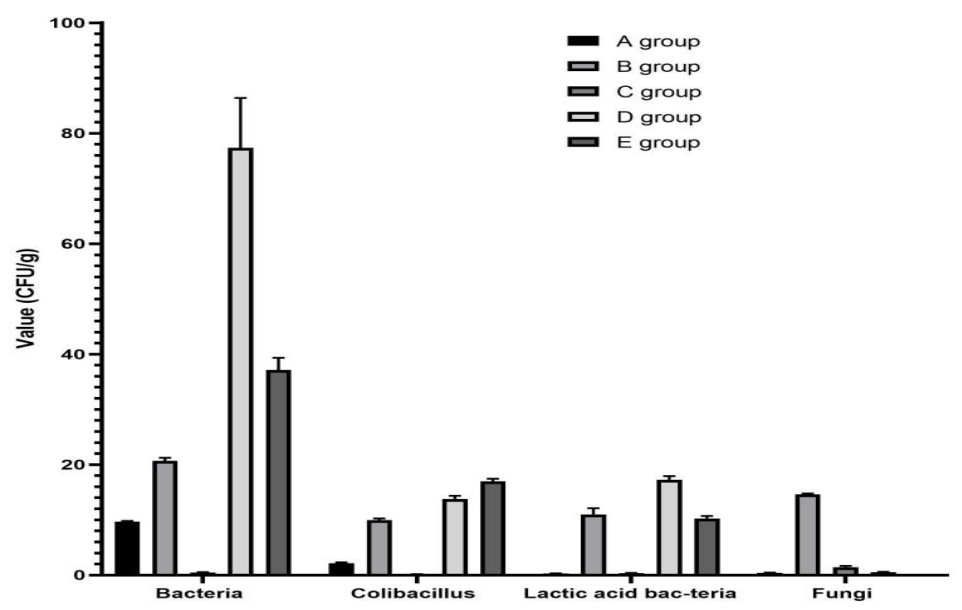

Fig. 4: Effects of different modeling methods on intestinal microbes 
the choice of TCM treatment has a good practical significance. To prepare a stable intestinal flora disorder model and study the efficacy of related effective TCM compound prescription can promote the research and application of TCM compound prescription in the treatment of intestinal flora-related diseases, and provide a reliable experimental animal model. In this study, 6 kinds of antibiotics commonly used in the clinic were selected to construct the splenoasthenic diarrhea model of flora imbalance, and the intestinal microecological mechanism of splenoasthenic diarrhea model constructed by Dachenqi Tang was analyzed. Studies have shown that Dachenqi Tang can cause splenoasthenic diarrhea quickly and seriously, spleen deficiency syndrome appeared after long time treatment, while it has little effect on the intestinal microorganisms. In the antibiotic modeling group, from the results of external characteristics, body weight changes and the effects on intestinal microorganisms, the modeling effect of gentamicin sulfate combined with cefradine was the best. It's mainly because their antibacterial spectrum could reach the maximum complementarity, and the mixture does not invalidate the drug.

Qiwei Baizhu powder was taken from the Decoction of Four Mild Drugs ${ }^{[17]}$, with the function of invigorating Qi and strengthening the spleen. The Decoction of Four Mild Drugs contains codonopsis pilosula, atractylodes macrocephala, Poria cocos and licorice. A large number of studies have confirmed that the Decoction of Four Mild Drugs can regulate intestinal flora disorders ${ }^{[18]}$. On the basis of Decoction of Four Mild Drugs, Qiwei Baizhu powder added three kinds of herbs, radices saussureae, wrinkled giant hyssop and the root of kudzu vine. Modern studies have confirmed that the mechanism of atractylodes macrocephala in the treatment of gastrointestinal diseases is mainly to provide gastrointestinal motility and gastric mucosal protection. Also, it can be used for anti-tumor, antioxidation, prevention of senile dementia and antiinflammation $^{[19]}$. Codonopsis pilosula has the functions of increasing appetite, promoting body growth, enhancing body immunity, promoting the increase of blood cells and improving the blood system ${ }^{[20]}$. Poria cocos have the effect of anti-tumor and enhancing immunity. Wrinkled giant hyssop contains volatile oil that can promote the secretion of gastric juice and enhance digestion, and has gastrointestinal spasmolysis, astringing to stop diarrhea, and antifungal effect ${ }^{[21]}$. The root of kudzu vine has the effects of reducing blood press, dilate coronary vessels, inhibit arteriosclerosis, anti-oxygen free radicals and anti-tumor ${ }^{[22]}$. Daidzin of the root of kudzu vine has an obvious spasmolysis effect on the isolated intestine. Radices saussureae has the effects of anti-inflammation and anti-splenoasthenic diarrhea, and anti-inflammation is the main mechanism of anti-splenoasthenic diarrhea. Radices saussureae contains costunolide and dehydro- $\alpha$-curcumene, which has relaxing smooth muscle and spasmolysis effect. Licorice has the function of enriching qi and regulating the middle warmer, and harmonizing various drugs. Its main component flavonoids have an inhibitory effect on gram-positive bacteria. From the pharmacological effects of a single medicine, it can be seen that immune function and gastrointestinal motility

TABLE 3: EFFECT OF QIWEI BAIZHU POWDER ON INTESTINAL MICROBIAL QUANTITY IN MODEL MICE

\begin{tabular}{lcccc}
\hline \multirow{2}{*}{ Group } & Bacteria & Colibacillus & Lactic acid bacteria & Fungi \\
\cline { 2 - 5 } A Group & $\left(10^{8}\right.$ CFU/g) & $\left(10^{7}\right.$ CFU/g) & $\left(10^{7}\right.$ CFU/g) & $\left(10^{7}\right.$ CFU/g) \\
B Group & $6.085 \pm 0.6008$ & $45.412 \pm 6.0851$ & $25.851 \pm 2.0775$ & $26.216 \pm 7.0478$ \\
C Group & $5.867 \pm 0.2241$ & $11.083 \pm 2.2554$ & $42.325 \pm 3.0491$ & $22.644 \pm 1.0099$ \\
D Group & $5.108 \pm 0.4389$ & $21.132 \pm 3.2795$ & $36.423 \pm 2.3944$ & $26.723 \pm 1.2177$ \\
E Group & $5.831 \pm 0.5623$ & $3.245 \pm 0.4307$ & $5.137 \pm 0.5613$ & $0.033 \pm 0.0014$ \\
\hline
\end{tabular}

TABLE 4: EFFECTS OF ULTRA-MICRO QIWEI BAIZHU POWDER ON THE NUMBER OF INTESTINAL MICROBES IN MODEL MICE

\begin{tabular}{|c|c|c|c|c|}
\hline Group & $\begin{array}{r}\text { Bacteria } \\
10^{8}\end{array}$ & Colibacillus & Lactic acid bacteria & $\begin{array}{c}\text { Fungi } \\
\left.10^{7}(5) / q\right)\end{array}$ \\
\hline A Group & $6.085 \pm 0.6008$ & $45.412 \pm 6.0851$ & $25.851 \pm 2.0775$ & $26.216 \pm 7.0478$ \\
\hline B Group & $5.867 \pm 0.2241$ & $11.083 \pm 2.2554$ & $42.325 \pm 3.0491$ & $22.644 \pm 1.0099$ \\
\hline C Group & $5.108 \pm 0.4389$ & $21.132 \pm 3.2795$ & $36.423 \pm 2.3944$ & $26.723 \pm 1.2177$ \\
\hline D Group & $5.831 \pm 0.5623$ & $3.245 \pm 0.4307$ & $5.137 \pm 0.5613$ & $0.033 \pm 0.0014$ \\
\hline E Group & $6.924 \pm 0.6142$ & $2.351 \pm 0.6641$ & $3.471 \pm 0.3487$ & $0.023 \pm 0.0028$ \\
\hline
\end{tabular}


were the significant pharmacological characteristics of Qiwei Baizhu powder ${ }^{[23]}$. At present, the research on the therapeutic mechanism of Qiwei Baizhu powder is mainly based on the analysis of immunological indexes. This study aims to explore the therapeutic mechanism of Qiwei Baizhu powder from the regulating effect of Qiwei Baizhu powder on the imbalance of intestinal flora caused by different modeling methods. The results showed that Qiwei Baizhu powder could regulate the imbalance of flora, and the number of lactic acid bacteria and fungi was significantly higher than that in the normal intestinal tract. It indicates that there were some probiotics in Qiwei Baizhu powder, which could promote the growth of lactic acid bacteria and fungi in the intestinal tract. There are many reports about the existence of probiotic-like substances in TCM compound prescription ${ }^{[24]}$. However, it is not possible to determine which specific active substances in Qiwei Baizhu powder play the role of probiotics now, which needs to be analyzed in combination with the effective chemical components of the seven medicines. Wrinkled giant hyssop has an antifungal effect, which is contrary to the results of this study, and the reason remains to be further confirmed.

\section{Acknowledgments}

The work was supported by Fund of Young Scholars from Administration of Traditional Chinese Medicine of Jilin Province (No. 2019048), "Study on the protective effect of Schisandrin B micelle on SH-SY5Y cells".

\section{Conflict of Interests:}

The authors declared no conflict of interest.

\section{REFERENCES}

1. Wu XN. Current concept of Spleen-Stomach theory and Spleen deficiency syndrome in TCM. World J Gastroenterol 1998;4(1):2.

2. Longhui C, Zemin Y, Weiwen C, Ruliu L, Chuanquan L, Lihua $\mathrm{G}$, et al. Differential expression of immune-related genes between healthy volunteers and type 2 diabetic patients with spleen-deficiency pattern. J Tradit Chin Med 2015;35(6):64652.

3. Xiong B, Qian H. Effects of Sijunzi decoction and Yupingfeng powder on expression of janus kinase-signal transducer and activator of transcription signal pathway in the brain of spleendeficiency model rats. J Tradit Chin Med 2013;33(1):78-84.

4. Zhao N, Zhang W, Guo Y, Jia H, Zha Q, Liu Z, et al. Effects on neuroendocrinoimmune network of Lizhong Pill in the reserpine induced rats with spleen deficiency in traditional Chinese medicine. J Ethnopharmacol 2011;133(2):454-9.

5. Zhang H, Wang J, Liu Y, Sun B. Glutinous rice amylopectin can adjust the plasma gut-regulated peptide levels in rhubarbinduced spleen deficiency rats. Food Funct 2016;7(2):938-42.
6. Chen YL, Chen WW, Wang YF, Li RL, Guo WF, Lao SX, et al. Bioinformatics research on chronic superficial gastritis of Pi-deficiency syndrome by gene arrays. Chin J Integr Med 2009;15(5):341-6.

7. Zhang XX, Chen WW, She B, Luo RJ, Shi N, Xue P, et al. The efficacy and safety of Jian-Wei-Qu-Tong Pills for the treatment of chronic non-atrophic gastritis (spleen and stomach qi deficiency with damp-heat stasis syndrome): study protocol for a phase II, randomized controlled trial. Trials 2014;15(1):272.

8. Wang L, Zhang L, Feng X, Xing L, Zhang W, Jiang K, et al. The functional difference of dendritic cells in $\mathrm{HBeAg}$ negative chronic hepatitis B patients with three different spleen deficiency syndromes and the therapeutic evaluation of chinese medicine intervention based on syndrome differentiation. Evid Based Complement Alternat Med; 2014.

9. Zhang S, Zhao L, Wang H, Wang C, Huang S, Shen H, et al. Efficacy of modified LiuJunZi decoction on functional dyspepsia of spleen-deficiency and qi-stagnation syndrome: a randomized controlled trial. BMC Complement Altern Med 2013;13(1):54.

10. Lederberg J. Infectious history. Science 2000;288(5464):28793.

11. Yang X, Xie L, Li Y, Wei C. More than 9,000,000 unique genes in human gut bacterial community: estimating gene numbers inside a human body. PLoS One 2009;4(6):e6074.

12. Kelly JR, Minuto C, Cryan JF, Clarke G, Dinan TG. Cross talk: the microbiota and neurodevelopmental disorders. Front Neurosci 2017;11:490.

13. O'Mahony SM, Clarke G, Borre YE, Dinan TG, Cryan JF. Serotonin, tryptophan metabolism and the brain-gutmicrobiome axis. Behav Brain Res 2015;277:32-48.

14. Takeda N, Ikeda R, Ohba K, Kondo M. Bufotenine reconsidered as a diagnostic indicator of psychiatric disorders. Neuroreport 1995;6(17):2378-80.

15. Wang TT. Study on the relationship between the changes of intestinal flora and the development of colorectal. Shanghai Jiaotong University 2012.

16. Cuskin F, Lowe EC, Temple MJ, Zhu Y, Cameron EA, Pudlo $\mathrm{NA}$, et al. Human gut Bacteroidetes can utilize yeast mannan through a selfish mechanism. Nature 2015;517(7533):165-9.

17. De Faria Ghetti F, Oliveira DG, de Oliveira JM, De Castro LE, Cesar DE, Moreira AP. Influence of gut microbiota on the development and progression of nonalcoholic steatohepatitis. Eur J Nutr 2018;57(3):861-76.

18. Xu J, Bjursell MK, Himrod J, Deng S, Carmichael LK, Chiang HC, et al. A genomic view of the human-Bacteroides thetaiotaomicron symbiosis. Science 2003;299(5615):2074-6.

19. Kelly D, Campbell JI, King TP, Grant G, Jansson EA, Coutts $\mathrm{AG}$, et al. Commensal anaerobic gut bacteria attenuate inflammation by regulating nuclear-cytoplasmic shuttling of PPAR- $\gamma$ and RelA. Nat Immunol 2004;5(1):104-12.

20. Sumizu K. Oxidation of hypotaurine in rat liver. Biochim Biophys Acta 1962;63(1):210-2.

21. Yuan L, Bambha K. Bile acid receptors and nonalcoholic fatty liver disease. World J Hepatol 2015;7(28):2811.

22. Ridlon JM, Kang DJ, Hylemon PB. Bile salt biotransformations by human intestinal bacteria. J Lipid Res 2006;47(2):241-59.

23. Dawson PA, Karpen SJ. Intestinal transport and metabolism of bile acids. J Lipid Res 2015;56(6):1085-99.

24. Martin FP, Dumas ME, Wang Y, Legido-Quigley C, Yap IK, Tang H, et al. A top-down systems biology view of microbiomemammalian metabolic interactions in a mouse model. Mol Syst Biol 2007;3(1):112.. 